\title{
IN VIVO ACCURACY OF TWO RADIOGRAPHIC SYSTEMS IN THE DETECTION OF BJÖRK-SHILEY CONVEXO-CONCAVE HEART VALVE OUTLET STRUT SINGLE LEG SEPARATIONS
}

Kenneth D. Hopper, MD Ian C. Gilchrist, MD ${ }^{\mathrm{b}}$

J. Richard Landis, $\mathrm{PhD}^{\mathrm{c}}$

Amir H. Abolfathi, MS

A. Russell Localio, MPH, MS

Ronald P. Wilson, VMD, MS

Walter E. Pae, Jr., MD

Allen R. Kunselman, $\mathrm{MA}^{\mathrm{c}}$

David W. Wieting, $\mathrm{PhD}^{\mathrm{f}}$

James W. Griffith, DVM ${ }^{\mathrm{d}}$

William S. Pierce, MD $^{\mathrm{e}}$

Paul S. Potok, DO ${ }^{\mathrm{a}}$

Thomas R. TenHave, $\mathrm{PhD}^{\mathrm{c}}$

James G. Chandler, MD
Objective: Modified cineradiographic systems have been used clinically to detect partially broken outlet struts in normally functioning Björk-Shiley convexo-concave heart valves. Almost all such valves were explanted, presuming that full failure would likely follow. Inasmuch as the clinical setting only rarely permits examination of normally rated valves, the accuracy of radiographic detection cannot be clinically defined. This study uses the clinical radiographic technique in sheep implanted with knownstatus convexo-concave valves, comparing its accuracy and that of a newly developed, geometric image magnification radiography system. Methods: Twenty-one sheep with mitral convexo-concave valves were studied on both systems. Five were used for extensive training. When operators were expert with both systems, images of four intact valves and 12 valves with outlet strut single leg separations, along with a seventeenth single leg separation valve used for calibration, were integrated into 112 image sets organized into a balanced incomplete block design for evaluation by eight trained, blinded reviewers. Results: Cineradiography sensitivity was $24 \%$ versus $31 \%$ for direct image magnification. The odds ratio for detection of single leg separation by direct image magnification versus cineradiography was 2.0 (95\% confidence interval, 0.76 to $5.9 ; p=0.13$ ). Cineradiography specificity was $93 \%$ versus $90 \%$ for direct image magnification. Sensitivity and specificity varied markedly by reviewer, with sensitivity ranging from $8 \%$ to $\mathbf{5 5 \%}$ and specificity from $\mathbf{5 1 \%}$ to $\mathbf{1 0 0 \%}$ for the combined technologies. Conclusions: The data support the need for more intensive training for convexo-concave valve imaging and further investigation of unconventional radiographic technologies. Clinical cineradiography of convexo-concave valves may detect as little as $25 \%$ of valves having a single leg separation, underestimating the prevalence of single leg separations and thereby implying more rapid progression to full fracture than is actually the case. (J Thorac Cardiovasc Surg 1998;115:582-90)
From the Department of Radiology, ${ }^{\mathrm{a}}$ Division of Cardiology, Department of Medicine, Center for Biostatistics and Epidemiology, ${ }^{\mathrm{c}}$ Department of Comparative Medicine, ${ }^{\mathrm{d}}$ Department of Cardiothoracic Surgery, ${ }^{\mathrm{e}}$ College of Medicine, Pennsylvania State University, Hershey, Pa., and the Shiley Heart Valve Research Center, ${ }^{\mathrm{e}}$ Irvine, Calif.

Supported by an unrestricted grant from the Shiley Heart Valve Research Center.

Received for publication June 5, 1997; revisions requested July 15, 1997; revisions received Nov. 24, 1997; accepted for publication Nov. 24, 1997.

Address for reprints: Kenneth D. Hopper, MD, Department of Radiology Pennsylvania State University, 500 University Dr., P.O. Box 850, Hershey, PA 17033.

Copyright (C) 1998 by Mosby, Inc.

$0022-5223 / 98 \$ 5.00+0 \quad \mathbf{1 2 / 1 / 8 7 7 9 6}$
The Björk-Shiley convexo-concave $(\mathrm{C} / \mathrm{C})$ valve was introduced in 1979 for aortic and mitral valve replacement. ${ }^{1,2}$ The valve has a pyrolytic carbon disc occluder that rotates about an inlet strut that is an integral part of the flange. Translation and rotation of the disc are restrained by an outlet strut that has two legs welded into the metal flange (Fig. 1). Between 1979 and 1986, approximately 86,000 $\mathrm{C} / \mathrm{C}$ valves were believed to have been implanted worldwide. Shiley, Inc. (Irvine, Calif.) estimates that $41,000 \mathrm{C} / \mathrm{C}$ valves are currently implanted in living patients.

In certain cases, $\mathrm{C} / \mathrm{C}$ valves have had mechanical failure wherein both legs of the outlet strut break from the flange, leaving nothing to retain the disc 


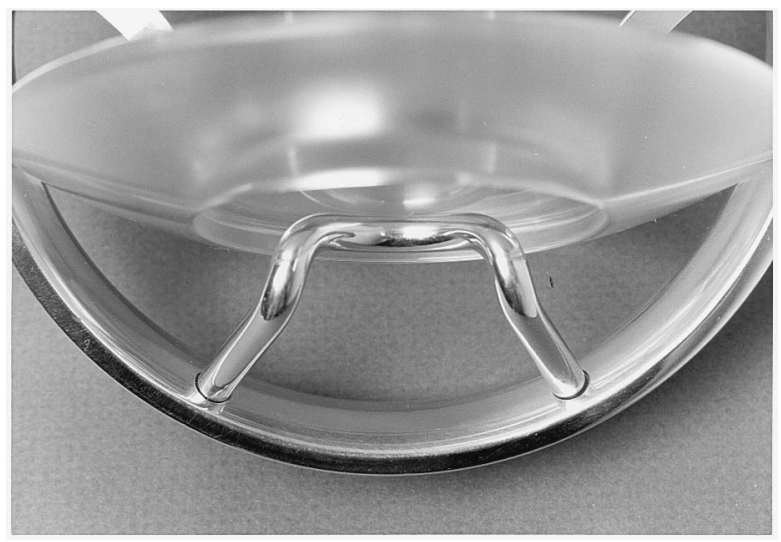

Fig. 1. An oversized model. The $\mathrm{C} / \mathrm{C}$ valve has a round convexo-concave pyrolytic carbon disc occluder that rotates around the inlet strut. Rotation and translation of this disc are restrained by an outlet strut held in place by two legs welded to the metal flange.

and causing abrupt and total valve incompetence. There is circumstantial evidence that fracture of one leg (SLS: single leg separation) precedes full outlet strut fracture. As a result, extensive efforts have been devoted to finding a reliable method of detecting an SLS. The most promising screening technique to date has been the Siemens Hicor-Coroskop cineradiographic system (Siemens Inc., Islin, N.J.) modified to seek exposures at 80 to $120 \mathrm{kVp}$ with a larger $35 \mathrm{~mm}$ image, obtained by using a $135 \mathrm{~mm}$ camera lens rather than the standard $80 \mathrm{~mm}$ camera lens (Fig. 2).

We have used an animal model developed by Shiley using sheep with $\mathrm{C} / \mathrm{C}$ valve mitral implants to estimate the accuracy of clinical SLS detection. The identical Siemens Hicor-Coroskop cineradiographic technique used clinically was evaluated under precisely controlled conditions using known-status valves and was compared with a newly developed geometric magnification radiography system. Feinfocus (feinfocus Medizintechnik GmbH, Garbsen, Germany), a manufacturer of high-resolution industrial x-ray equipment to image through dense materials such as metal, provided a two-of-a-kind prototype (DIMA Cor C22) geometric magnification radiography system for our use. While static images (Fig. 3) and in vitro scanning, using a working heart phantom, have been encouraging, this new modality has previously had only a cursory in vivo evaluation in animals ${ }^{3}$ and man. Both systems were evaluated by blinded imaging using a comprehensive scien-

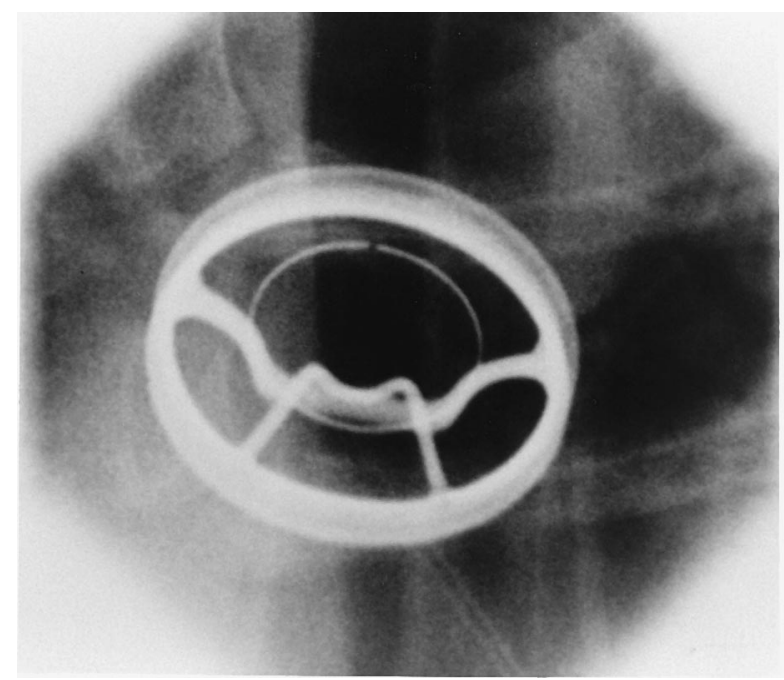

Fig. 2. This valve was removed from a patient for reasons other than a known SLS. On closer examination, it was found to have a zero-gap left SLS. As imaged in vitro, on a modified Siemens cineradiographic system, the defect just above the strut leg base is obvious.

tific design and expert readers from Shiley's clinical study sites and our own institution.

\section{Materials and methods}

Twenty-one $29 \mathrm{~mm} \mathrm{C/C}$ valves (18 with a 60-degree opening angle and three with a 70-degree opening angle) were implanted via a left thoracotomy as mitral replacements in anesthetized young adult Suffolk sheep. All animal procedures and care followed guidelines issued by the National Society for Medical Research and the National Institutes of Health. ${ }^{4,5}$ Five of the implanted valves were for screening practice: two were intact and three had intentional, mechanically induced SLSs. The remaining 16 study sheep received four intact valves, seven valves with intentional SLS, and five clinical SLS valves. The mechanically induced SLSs were adjusted to place the breaksurfaces in contact with less than $300 \mu \mathrm{m}$ of offset between the two ends. The clinical SLS valves had been explanted from patients for reasons other than the result of radiographic screening. The status of all valves was verified by electron microscopy to be either intact or to have an SLS with limited offset (shift of strut alignment at the point of separation) and zero gap (strut sections remained in contact at the point of offset).

Extensive training of and practice by the two imaging teams were carried out on a modified Siemens HicorCoroskop system and the feinfocus system, respectively. Both systems were operated at peak energy $(\mathrm{kVp}$ : kilovoltage peak) so as to better detect $\mathrm{C} / \mathrm{C}$ valve metallic defects. ${ }^{6}$ Experience was gained with both systems using a mechanical heart phantom, ${ }^{7}$ which approximated the normal attenuation of the human thorax and cardiac mitral valve motion. ${ }^{8}$ The actual study was initiated only after the capabilities of both imaging teams were approved by the 


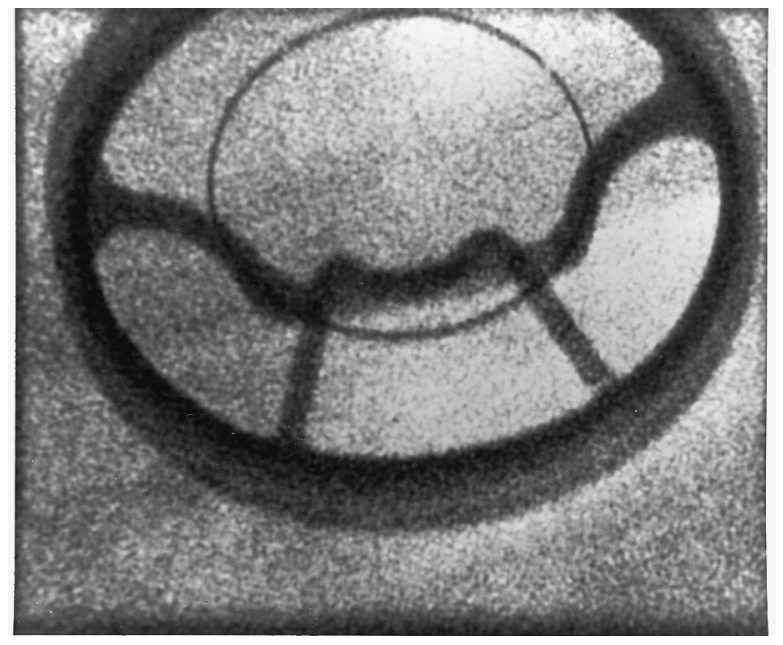

Fig. 3. This valve was also prophylactically replaced without knowledge of its outlet strut status. On removal, the valve was found to have a zero-gap left SLS. As imaged in vitro on the feinfocus system, the defect in the base of the left outlet strut leg is obvious.

Shiley Heart Valve Research Center. The two systems and the training are fully described in Appendix A.

Separations of the outlet strut typically occur in or near the welds to the metal flange. In imaging these welds, the Shiley Heart Valve Research Center has developed five separate projections (views). The principal view profiles both welds away from the metal flange and has been termed the "tunnel view" (Figs. 2 and 3). Internal and external oblique views of each outlet strut demonstrate each weld from two additional projections. A total of five views of each valve are possible. Because the tunnel view images both outlet strut welds, three views of each outlet strut were actually obtained.

The 16 study sheep, plus one sheep with a zero-gap, intentional SLS (used to generate a "calibration" set for the readers), were imaged in a randomized order on both systems. Each team (blinded to the valve status), the number of imaging sessions scheduled, and the findings of the other team optimized the visualization of both outlet strut welds, obtaining five views per valve. A navigational computer program assisted in initial C-arm positioning, saving scanning time. ${ }^{9}$ Radiation exposure was directly measured on both systems by an air exposure product meter placed within the x-ray beam (Diamentor, model M2, PTW, Freiburg, Germany). ${ }^{10}$

The acquired five views of each valve were prepared for reading according to a balanced incomplete block design $^{11}$ requiring 28 blocks of 16 image sets each and eight reviewers (Fig. 4). This design facilitated the large number of reviews needed to obtain adequate statistical power and a realistic SLS prevalence with only a limited number of study sheep. Each "image set" included a single tunnel view and two oblique views. Each block included image sets from the single calibration SLS valve, from one or two SLS valves, and from 13 to 14 intact valve image sets. The

\begin{tabular}{|c|c|c|c|c|c|c|c|c|}
\hline \multirow[b]{2}{*}{ Block Number } & \multicolumn{8}{|c|}{ Reviewer } \\
\hline & 1 & 2 & 3 & 4 & 5 & 6 & 7 & 8 \\
\hline 1 & $\mathrm{x}$ & $\mathrm{x}$ & & & & & & \\
\hline 2 & & & $\mathrm{X}$ & $\mathrm{X}$ & & & & \\
\hline 3 & & & & & $\mathrm{X}$ & $\mathrm{X}$ & & \\
\hline 4 & & & & & & & $\mathrm{X}$ & $\mathrm{X}$ \\
\hline 5 & $\mathrm{x}$ & & $\mathrm{x}$ & & & & & \\
\hline 6 & & $\mathrm{X}$ & & & & & & $\mathrm{X}$ \\
\hline 7 & & & & $\mathrm{X}$ & $\mathrm{X}$ & & & \\
\hline 8 & & & & & & $\mathrm{X}$ & $\mathrm{X}$ & \\
\hline 9 & $\mathrm{X}$ & & & $\mathrm{X}$ & & & & \\
\hline 10 & & $\mathrm{X}$ & & & & & $\mathrm{X}$ & \\
\hline 11 & & & $\mathrm{x}$ & & & $\mathrm{X}$ & & \\
\hline 12 & & & & & $\mathrm{X}$ & & & $\mathrm{X}$ \\
\hline 13 & $\mathrm{X}$ & & & & $\mathrm{X}$ & & & \\
\hline 14 & & $\mathrm{X}$ & $\mathrm{X}$ & & & & & \\
\hline 15 & & & & $\mathrm{x}$ & & & $\mathrm{x}$ & \\
\hline 16 & & & & & & $\mathrm{X}$ & & $\mathrm{X}$ \\
\hline 17 & $\mathrm{X}$ & & & & & $\mathrm{X}$ & & \\
\hline 18 & & $\mathrm{X}$ & & $\mathrm{X}$ & & & & \\
\hline 19 & & & $\mathrm{X}$ & & & & & $\mathrm{X}$ \\
\hline 20 & & & & & $\mathrm{x}$ & & $\mathrm{x}$ & \\
\hline 21 & $\mathrm{X}$ & & & & & & $\mathrm{X}$ & \\
\hline 22 & & $\mathrm{X}$ & & & & $\mathrm{X}$ & & \\
\hline 23 & & & $\mathrm{X}$ & & $\mathrm{X}$ & & & \\
\hline 24 & & & & $\mathrm{X}$ & & & & $\mathrm{X}$ \\
\hline 25 & $\mathrm{X}$ & & & & & & & $\mathrm{X}$ \\
\hline 26 & & $\mathrm{X}$ & & & $\mathrm{x}$ & & & \\
\hline 27 & & & $X$ & & & & $X$ & \\
\hline 28 & & & & $\mathrm{X}$ & & $\mathrm{X}$ & & \\
\hline
\end{tabular}

Fig. 4. Balanced incomplete block design for eight reviewers. Each block contained 16 image sets per modality, each consisting of three views. Each image set was read by two reviewers. Each reviewer read seven blocks, or $16 \times$ $7=112$ image sets per modality for a total of 224 image sets.

design alternatively paired each of the eight reviewers such that each block was read twice (Fig. 4). Each reviewer read seven blocks of image sets per modality (112 sets) for a total of 224 image sets. Prevalence of SLSs among the 1792 image sets (896 per modality) ranged from $15 \%$ to $19 \%$, as seen by any one reviewer. All aspects of the study design were blinded to the eight readers. No member of either imaging team served as a reader or had contact with any reader before or during the image interpretation sessions.

Interpretation was by predetermined criterion (Table I) with an interval scoring, called an image assessment grade, from 1 (normal) to 5 (definite SLS). The diagnostic threshold of an SLS was varied using all possible cut points along the image assessment grade scale. Sensitivity (proportion of correctly identified normal valves) estimates were calculated for each modality and reviewer, as well as for all reviewers combined. From these sensitivity 
Table I. Grading criteria

\begin{tabular}{|c|c|}
\hline Grade & Description \\
\hline \multicolumn{2}{|c|}{$\begin{array}{l}\text { Siemens assessment } \\
\text { grades }\end{array}$} \\
\hline 1 & Apparently normal \\
\hline 2 & $\begin{array}{l}\text { Minimally suspicious: SLS appearance in } \\
\text { one or two frames in one view only }\end{array}$ \\
\hline 3 & $\begin{array}{l}\text { Suspicious: appearance in several ( } 5 \% \text { to } \\
10 \% \text { ) frames in one view, or one or } \\
\text { two frames in two views }\end{array}$ \\
\hline 4 & $\begin{array}{l}\text { Probable SLS: appearance in multiple } \\
(>10 \%) \text { frames in one view, or several } \\
(5 \% \text { to } 10 \%) \text { frames in two views }\end{array}$ \\
\hline 5 & $\begin{array}{l}\text { Definite SLS: appearance in multiple } \\
\quad(>10 \%) \text { frames in more than one view }\end{array}$ \\
\hline \multicolumn{2}{|c|}{$\begin{array}{l}\text { Feinfocus assessment } \\
\text { grades }\end{array}$} \\
\hline 1 & Apparently normal \\
\hline 2 & $\begin{array}{l}\text { Minimally suspicious: SLS appearance in } \\
\text { one frame }\end{array}$ \\
\hline 3 & $\begin{array}{l}\text { Suspicious: SLS appearance in two } \\
\text { frames in one view }\end{array}$ \\
\hline 4 & $\begin{array}{l}\text { Probable SLS: appearance in two frames } \\
\text { in one view }+ \text { one frame in another } \\
\text { view }\end{array}$ \\
\hline 5 & $\begin{array}{l}\text { Definite SLS: appearance in two frames } \\
\text { or more in more than one view }\end{array}$ \\
\hline
\end{tabular}

and specificity estimates, receiver operating characteristic curves were generated to compare the modalities. Adopting clinical conventions in assessing the likelihood of an SLS, we used an image assessment grade of 4 or 5 to represent a finding of SLS and a grade of 1, 2, or 3 to represent a finding of normal.

\section{Results}

Considering all reviews except those of the calibration valve, sensitivity (fraction of correctly identified SLS valves) of the feinfocus technology $(31 \%, 30$ of 96$)$ appeared higher than that of the modified Siemens system $(24 \%, 23$ of 96) (Table II). However, this difference was not statistically significant at conventional levels; the adjusted odds ratio of detecting an SLS by feinfocus compared with Siemens was $2.0(95 \%$ confidence interval $[\mathrm{CI}], 0.76$ to $5.9 ; p=0.13)$. Specificity (fraction of correctly identified intact valves) of the Siemens system $(93 \%, 695$ of 744) was higher than that of the feinfocus system $(90 \%, 668$ of 744) (odds ratio $=1.96,95 \% \mathrm{CI}, 1.2$ to $3.2 ; p=$ $0.003)$. The area under the receiver operating characteristic curve for feinfocus was slightly greater than for the Siemens system when the data were analyzed using all possible cut points along the image assessment grade scale (Fig. 5). Previously reported phantom and clinical studies $8,9,15$
Table II. Sensitivity and specificity by reviewer*

\begin{tabular}{|c|c|c|c|c|}
\hline \multirow[b]{3}{*}{ Reviewer } & \multicolumn{4}{|c|}{ Imaging technology } \\
\hline & \multicolumn{2}{|c|}{ Feinfocus } & \multicolumn{2}{|c|}{ Siemens } \\
\hline & $\begin{array}{c}\text { Sensitivity } \\
(\%)\end{array}$ & $\begin{array}{c}\text { Specificity } \\
(\%)\end{array}$ & $\begin{array}{c}\text { Sensitivity } \\
(\%)\end{array}$ & $\begin{array}{c}\text { Specificity } \\
(\%)\end{array}$ \\
\hline 1 & $27(3 / 11)$ & $98(92 / 94)$ & $18(2 / 11)$ & $99(93 / 94)$ \\
\hline 2 & $30(3 / 11)$ & $99(94 / 95)$ & $20(2 / 10)$ & $99(94 / 95)$ \\
\hline 3 & $55(6 / 11)$ & $51(48 / 94)$ & $45(5 / 11)$ & $55(52 / 94)$ \\
\hline 4 & $36(5 / 14)$ & $99(90 / 91)$ & $36(5 / 14)$ & $100(91 / 91)$ \\
\hline 5 & $23(3 / 13)$ & $100(92 / 92)$ & $23(3 / 13)$ & $100(92 / 92)$ \\
\hline 6 & $50(6 / 12)$ & $83(77 / 93)$ & $33(4 / 12)$ & $97(90 / 93)$ \\
\hline 7 & $25(3 / 12)$ & $94(87 / 93)$ & $8(1 / 12)$ & $100(93 / 93)$ \\
\hline 8 & $8(1 / 13)$ & $96(88 / 92)$ & $8(1 / 13)$ & $98(90 / 92)$ \\
\hline $\begin{array}{l}\text { All eight } \\
\text { reviewers }\end{array}$ & $31(30 / 96)$ & $90(668 / 744)$ & $24(23 / 96)$ & $93(695 / 744)$ \\
\hline
\end{tabular}

*An image assessment grade of 4 or 5 was considered as a positive SLS finding. The calibration valve is not included in the table.

plus the results presented here have used a cut point of 4 to define an SLS.

The single calibration valve (an SLS), not included in the previous results, was viewed 56 times for each imaging modality, that is, seven times per reviewer per modality. The sensitivity was $36 \%$ (20 of 56) for the feinfocus system and $9 \%$ (5 of 56) for the Siemens system (adjusted odds ratio $=8.5,95 \%$ CI, 2.0 to $76 ; p=0.0007$ ).

Rates of sensitivity and specificity varied markedly by reviewer (see Table II). For the feinfocus system, sensitivity ranged from $8 \%$ to $55 \%$ and specificity from $51 \%$ to $100 \%$. For the Siemens system, the ranges were equally wide: $8 \%$ to $45 \%$ for sensitivity and $55 \%$ to $100 \%$ for specificity. The same variation appeared in the calibration SLS valve: sensitivities ranged from $0 \%$ to $86 \%$ for the feinfocus system and from $0 \%$ to $43 \%$ for the Siemens system. Two reviewers appeared to fare worse than the others on both imaging systems. Reviewer 3 exhibited much lower specificity (51\% and $55 \%$ ) than his peers; reviewer 8 exhibited much lower sensitivity $(8 \%)$ with the feinfocus system, as well as a low sensitivity with the Siemens system $(8 \%)$. A third reviewer (reviewer 7) also performed markedly worse than others in detecting SLS valves on the Siemens system. Eliminating reviewers 3 and 8 does not change the overall results because their aberrant performances offset each other.

Valve-specific results are displayed in Table III. On one extreme, two SLS valves, both clinical SLSs, were easily identified by means of both technologies (valves 11 and 12). On the other extreme, three were never seen on either technology (valves 3,5, and 10). 


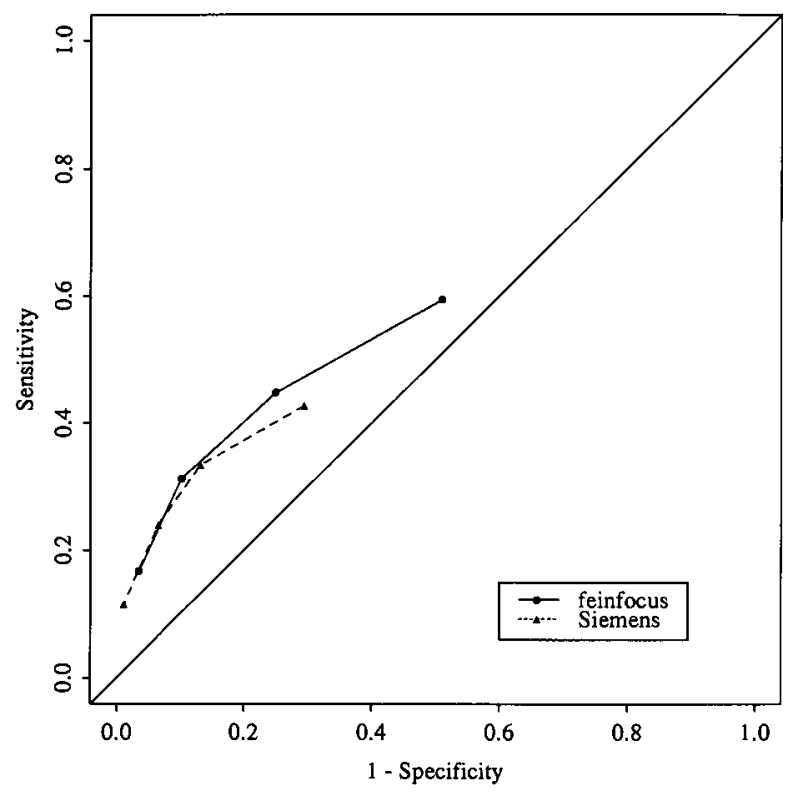

Fig. 5. Receiver operating characteristic curves for all eight reviewers (excludes the calibration valve) comparing the diagnostic accuracy of the feinfocus and Siemens systems. The curves are based on 840 readings per modality scored from 1 to 5 (Table I). Sensitivity and specificity were computed by selecting all possible cut points along the 5-point scale to represent the boundaries between positive and negative findings of an SLS.

Between these two extremes, the differences in the two technologies appear in the imaging of specific valves, for example, valves 1 and 4 . Taking the five clinical valves as a whole over both technologies, SLSs were detected in 40 of 80 cases $(50 \%)$; by contrast, the seven intentional SLSs (excluding the calibration) were detected significantly less often (13 of 112 cases, $12 \% ; p<0.001)$.

Radiation levels of the feinfocus system were significantly lower than those for the Siemens system (difference $=1197 R \cdot \mathrm{cm}^{2}, 95 \% \mathrm{CI}=796$ to 1597 , $p=0.00001)$ (paired $t$ test).

\section{Discussion}

The first report of an outlet strut fracture appeared shortly after the $\mathrm{C} / \mathrm{C}$ valve's introduction. ${ }^{12}$ As of June 30, 1997, 603 outlet strut fractures have been reported to the manufacturer, approximately two thirds of which have been fatal. Failure to detect and report outlet strut fractures, especially among older patients with sudden death, is now compensated in Shiley's estimates of fracture incidence, using two known cohorts ${ }^{13,14}$ for calibration. ${ }^{15}$ The risk of outlet strut fracture varies from $0.01 \%$ to $3.29 \%$ per year depending on valve size, opening angle, implant position, weld date, and welder group. Weld dates in 1981 and early 1982, $29 \mathrm{~mm}$ flange size, 70-degree opening angle, and mitral implants in younger men indicated a greater likelihood of breakage. ${ }^{15}$

The Shiley Heart Valve Research Center instituted a wide range of research efforts to find a noninvasive screening method to detect $\mathrm{C} / \mathrm{C}$ valves in which one of the two outlet strut legs may have separated from the flange-a single leg separation (SLS). Animal and in vitro studies have shown that the $\mathrm{C} / \mathrm{C}$ valve apparently functions normally until both outlet strut legs separate from the flange and outlet strut fracture occurs. An SLS appears to be a precursor to complete outlet strut fracture and disc embolization. ${ }^{9}$

Radiographic studies have correctly identified one aortic and 25 mitral SLS valves, incurring four false positives and one verified false negative in the process of studying $964 \mathrm{C} / \mathrm{C}$ valves with an annual risk of fracture of $0.1 \%$ or more in 842 patients. ${ }^{15}$ Because almost $90 \%$ of the study valves received negative ratings and remain functioning in situ or buried with decedents, the accuracy of clinical radiographic SLS detection simply cannot be known. The radiographically detectable SLS prevalence was $3 \%$ in these higher epidemiologic-risk valves, implying a median SLS duration in the order of 2 years before fracture. ${ }^{9}, 15$ Inasmuch as the sensitivity is unknown, the actual prevalence may be much higher, implying longer persistence of the SLS condition and perhaps lesser need for valve replacement, particularly in older patients. ${ }^{16}$

Over the past several years, the Shiley Heart Valve Research Center has aggressively pursued all avenues of research that held any promise of providing a means of detecting $\mathrm{C} / \mathrm{C}$ valve SLSs in situ. The best of these, cineradiographic screening, has been studied in higher-risk $\mathrm{C} / \mathrm{C}$ valve patients in selected sites in the United States and Europe. However, until the present investigation, no in vivo assessment of radiographic detection sensitivity and specificity has been undertaken and no systematic evaluation of unconventional radiographic technologies has been done. The sheep was used in this study because its thorax mimics the scatter and attenuation encountered in human imaging. Our expert imagers and reviewers were able to achieve only overall $24 \%$ sensitivity, $12 \%$ in mechanically induced SLSs and 50\% in clinical SLS valves, sug- 
Table III. Valve-specific characteristics and percent correct classification*

\begin{tabular}{|c|c|c|c|c|c|c|c|}
\hline \multirow{2}{*}{\multicolumn{6}{|c|}{ Valve characteristics }} & \multicolumn{2}{|c|}{ Imaging technology } \\
\hline & & & & & & \multirow{2}{*}{$\begin{array}{c}\text { Feinfocus } \\
\text { Correct } \\
\text { classification } \\
(\%)\end{array}$} & \multirow{2}{*}{$\begin{array}{c}\text { Siemens } \\
\text { Correct } \\
\text { classification } \\
(\%)\end{array}$} \\
\hline $\begin{array}{l}\text { Valve } \\
\text { No. }\end{array}$ & $\begin{array}{c}\text { Opening } \\
\text { angle } \\
\text { (degree) }\end{array}$ & $\begin{array}{c}\text { True valve } \\
\text { status }\end{array}$ & $\begin{array}{l}S L S \\
\text { strut }\end{array}$ & $\begin{array}{c}S L S \\
\text { location }\end{array}$ & $\begin{array}{l}\text { Gap/offset } \\
\text { size }(\mu \mathrm{m})\end{array}$ & & \\
\hline $1 \dagger$ & 60 & Intentional SLS & Right & Shaft & $0 / 280.6$ & $36(20 / 56)$ & $9(5 / 56)$ \\
\hline 2 & 60 & Intentional SLS & Left & Flare & $0 / 29$ & $13(1 / 8)$ & $13(1 / 8)$ \\
\hline 3 & 60 & Intentional SLS & Left & Flare & $0 / 14.5$ & $0(\%)$ & $0(\%)$ \\
\hline 4 & 60 & Intentional SLS & Right & Flare & $0 / 128 / 5$ & $75(6 / 8)$ & $13(1 / 8)$ \\
\hline 5 & 60 & Intentional SLS & Right & Flare & $0 / 120.6$ & $0(\%)$ & $0(\%)$ \\
\hline 6 & 60 & Intentional SLS & Left & Flare & $0 / 193.5$ & $13(1 / 8)$ & $13(1 / 8)$ \\
\hline 7 & 60 & Intentional SLS & Right & Shaft & $0 / 29$ & $13(1 / 8)$ & $0(\%)$ \\
\hline 8 & 60 & Intentional SLS & Right & Shaft & $0 / 37$ & $0(\%)$ & $13(1 / 8)$ \\
\hline 9 & 60 & Clinical SLS & Left & Shaft & $0 / 132$ & $38(3 / 8)$ & $50(4 / 8)$ \\
\hline 10 & 70 & Clinical SLS & Left & Shaft & $0 / 63$ & $0(\%)$ & $0(\%)$ \\
\hline 11 & 70 & Clinical SLS & Right & Shaft & $0 / 139$ & $88(7 / 8)$ & $88(7 / 8)$ \\
\hline 12 & 60 & Clinical SLS & Left & Shaft & $0 / 151$ & $100(8 / 8)$ & $88(7 / 8)$ \\
\hline 13 & 60 & Clinical SLS & Left & Shaft & $0 / 229$ & $38(3 / 8)$ & $13(1 / 8)$ \\
\hline 14 & 60 & Intact & N/A & N/A & N/A & $89(166 / 186)$ & $86(160 / 186)$ \\
\hline 15 & 60 & Intact & N/A & N/A & N/A & $90(167 / 186)$ & $98(183 / 186)$ \\
\hline 16 & 70 & Intact & N/A & N/A & N/A & $91(169 / 186)$ & $98(183 / 186)$ \\
\hline 17 & 60 & Intact & N/A & N/A & N/A & $89(166 / 186)$ & $91(169 / 186)$ \\
\hline
\end{tabular}

$N / A$, Not applicable.

*An image assessment grade of 4 or 5 was considered as correct for true SLS valves; an image assessment grade of 1,2 , or 3 was considered as correct for true normal (non-SLS) valves.

$\dagger$ Calibration valve.

gesting that this may be the range of sensitivity under similar controlled circumstances in human subjects. The implication is that two or three of four radiographed SLS valves might be undetected in patients going about their normal activities. The need for valve replacement based on a radiographically identified SLS may not be as great as presumed, because a higher true SLS prevalence means that progression to complete fracture either is less likely or takes a longer time than the radiographic prevalence suggests. ${ }^{16}$ In particular, older patients with substantial comorbidities might consider foregoing SLS valve replacement in view of the reported overall $15 \%$ operative mortality ${ }^{15}$ If the SLS condition can persist for years, this magnitude of operative risk might be unacceptable, save for younger patients with the highest risk-category valves.

Performance in this study varied by both reviewer and valve, suggesting that the abilities of Siemens and feinfocus technologies to detect SLSs in vivo depend heavily on the skills and experience of individual reviewers, as well as on the idiosyncrasies of individual SLSs. Individual reviewer sensitivities varied markedly, and overall reviewer performance varied widely by SLS valve. These results suggest that the overall performance not only is influenced by reviewer skills, but also is valve-specific, with some SLS valves identified correctly far more often than others.

Reviewer training and testing should improve the performance with these technologies, particularly with regard to specificity of the feinfocus system. For example, reviewer 3 overread nearly $50 \%$ of all image sets of normal valves as having an SLS. In contrast, several reviewers were nearly $100 \%$ correct when classifying image sets of normal valves, including reviewer 5, who was $100 \%$ correct for both technologies. One reviewer (reviewer 8) rarely identified an SLS with either technology.

Over all SLS valves, our results suggest a potential advantage for the feinfocus system, as summarized by a higher odds of detection with a small, but significant, loss of specificity, compared with the Siemens system. Improving sensitivity by seven percentage points means that out of 100 SLS valves, seven not detected by the Siemens system would potentially be identified by the feinfocus technology. The feinfocus system has been used on 12 patients with $\mathrm{C} / \mathrm{C}$ valves at one center in Europe, resulting in one false positive and no true positive detections (R. W. Günther, personal communication, 1996).

In dealing with patients having $\mathrm{C} / \mathrm{C}$ valves, espe- 
cially in the higher risk groups, there are three potential courses of action: elective explantation, screening, and expectant management. de $\mathrm{Mol}$ and associates ${ }^{17}$ have implied that prophylactic $\mathrm{C} / \mathrm{C}$ valve replacement should be given more frequent consideration. Among 24 elective explants from 21 patients without valve dysfunction, they discovered seven unanticipated SLSs (29\%). If the operative mortality was $0 \%$, as it was among these 21 patients (mean age 51 years), explantation might be the most advisable course of action for high-risk valves.

The operative mortality from elective valve replacement, however, has ranged from $3 \%$ to $5 \%$ for mitral valve surgery in high-volume centers. ${ }^{18-23}$ As with coronary bypass surgery, this mortality might increase with less experienced surgeons ${ }^{24}$ and in older patients with serious cardiovascular or other medical diseases. ${ }^{25-29}$ The operative mortality in 27 patients with radiographically suspected SLSs was $15 \%$. $^{9,15}$

Elective screening of all patients with a $\mathrm{C} / \mathrm{C}$ valve by a modified Siemens cineradiographic system is difficult to recommend on the basis of this study. With an overall prevalence of $11 \%$ (excluding the calibration valve data), the positive predictive value is $32 \%$ ( 23 of 72 ). Conversely, $68 \%$ of patients with positive test results might have normal valves. If the risk of operative mortality from explantation is about 5\%, then routine explantation for positive tests would result in approximately three unnecessary deaths (operative mortalities in normal valves) per 100 patients with positive screens $(68 \times 0.05)$. The negative predictive value is $90 \%$ (695 of 768) in our sample, which means that $10 \%$ of those with negative screening would potentially have SLS valves.

The hazard of eventual fracture and sudden death among patients with a C/C valve SLS remains uncertain. Although one should extrapolate from our sheep data that the real incidence of clinical SLSs is higher than has been recognized radiographically, indicating slower progression to complete fracture, the SLSs in this study were intentionally among the more difficult to image with zero gaps and limited offsets.

The data from this study do not support universal cineradiographic screening of patients with $\mathrm{C} / \mathrm{C}$ valves for SLS detection. They do indicate a need for more intensive training and selection of the physicians doing the scanning and image interpretation. With the SLS detection variability discovered in this study, perhaps pairing of the best readers would improve the sensitivity of radiographic screening. Last, the results of this study support further investigation of unconventional x-ray technologies such as direct image magnification in evaluating patients with $\mathrm{C} / \mathrm{C}$ valves.

\section{REFERENCES}

1. Björk VO. The improved Björk-Shiley tilting disc valve prosthesis. Scand J Thorac Cardiovasc Surg 1978;12:81-4.

2. Sethia B, Turner MA, Lewis S, Rudger RA, Bain WH. Fourteen years' experience with the Björk-Shiley tilting disc prosthesis. J Thorac Cardiovasc Surg 1986;91:350-61.

3. Cremer J, Boetel C, Fredow G, Gebureck P, Haverick A. Radiographic assessment of structural defects in Björk-Shiley convexo-concave prosthesis. Eur J Cardiothoracic Surg 1995; 9:373-7.

4. United States Food and Drug Administration. Good laboratory practices for nonclinical laboratory studies. Revised April 1, 1991.

5. United States Department of Health and Human Services, Public Health Service, National Institutes of Health. Guide for the care and use of laboratory animals. NIH Publication No. 86-23, revised 1985.

6. Abolfathi AH, Hirsch JL, Nissen SE, Wieting DW, Chandler JG. Effect of valve profiling and increasing $\mathrm{kVp}$ on in situ radiographic detection of single leg separations of the BjörkShiley Convexo-Concave heart valve. Proc Annual Int Conf IEEE Eng Med Biol Soc 1994;16:528-9.

7. Leyenaar HJ, Abolfathi AH, Bakalyra DM, Conlin $\mathrm{CH}$, Wieting DW, Chandler JC. A working cardiac valve phantom for radiographic assessment of prosthetic heart valves. Acad Radiol 1995;2:896-901.

8. Gilchrist IC, Cardella JF, Fox PS, et al. Radiographic detection of single-leg fracture in Björk-Shiley Convexo-Concave prosthetic valves: a phantom study. Am Heart J 1997;133: 197-202.

9. O'Neill WW, Chandler JC, Gordon RE, et al. Radiographic detection of strut separations in Björk-Shiley convexo-concave mitral valves. N Engl J Med 1995;333:414-9.

10. Shrimpton PC, Wall BF, Jones DG, Fisher ES. The measurement of energy impacted to patients during diagnostic x-ray examinations using the Diamentor exposure-area product meter. Phys Med Biol 1984;29:1199-208.

11. Cochran WG, Cox GM. Experimental designs. 2nd ed. New York: John Wiley; 1992. p. 473, plan 11.9.

12. Brubakk O, Simonsen S, Källman L, Fredriksen A. Strut fracture in the new Björk-Shiley mitral valve prosthesis. Thorac Cardiovasc Surg 1981;29:108-9.

13. van der Graaf Y, de Waard F, Van Herwerden LA, Defauw J. Risk of strut fracture of Björk-Shiley valves. Lancet 1992;339:257-61.

14. Ericsson A, Lindblom D, Semb G, et al. Strut fracture with the Björk-Shiley $70^{\circ}$ convexo-concave valve: an international multi-institutional follow-up study. Eur J Cardiothorac Surg 1992;6:339-46.

15. Chandler JG, Hirsch JL, O'Neill WW, et al. Radiographic detection of single strut leg separations as a putative basis for prophylactic explantation of Björk-Shiley Convexo-Concave heart valves. World J Surg 1996;20:953-60.

16. Grunkemeier GL. Invited commentary following Chandler JG, Hirsch JL, O'Neill WW, et al. Radiographic detection of 
single strut leg separations as a putative basis for prophylactic explantation of Björk-Shiley Convexo-Concave heart valves. World J Surg 1996;20:959.

17. de Mol BA, Kallenwaard M, McLellan RB, van Herwerden LA, Defauw JJ, van der Graff Y. Single-leg strut fractures in explanted Björk-Shiley valves. Lancet 1994;343:9-12.

18. Antunes MJ, Magalhäes MP. Isolated replacement of a prosthesis or a bioprosthesis in the mitral valve position. Am J Cardiol 1987;59:346-9.

19. Bortolotti U, Milano A, Mazzucco A, et al. Results of reoperation for primary tissue failure of porcine bioprostheses. J Thorac Cardiovasc Surg 1985;90:564-9.

20. English TAH, Milstein BB. Repeat open intracardiac operation. J Thorac Cardiovasc Surg 1978;76:56-60.

21. Husebye DG, Pluth LR, Piehler JM, et al. Reoperation on prosthetic heart valves. J Thorac Cardiovasc Surg 1983;86: 543-52.

22. Lyde BW, Cosgrove DM, Taylor PC, et al. Reoperations for valve surgery: perioperative mortality and determinants of risk for 1,000 patients, 1958-1984. Ann Thorac Surg 1986;43: 172-5.

23. Pansini S, Ottino G, Forsennan PG, et al. Reoperations of heart valve prosthesis: an analysis of operative risks and late results. Ann Thorac Surg 1990;50:569-96.

24. O'Connor GT, Plume SK, Olmstead EM, et al. A regional prospective study of in-hospital mortality associated with coronary artery by-pass grafting. JAMA 1991;266:803-9.

25. Grunkemeier GL, Chandler JG, Miller DC, Jamieson WR, Staff A. Utilization of manufacturers' implant card data to estimate heart valve failure. J Heart Valve Dis 1993;2:493503.

26. Blackstone EH, Kirklin JW. Recommendations for prophylactic removal of heart valve prostheses. J Heart Valve Dis 1992;1:3-14.

27. Scott WC, Miller DC, Haverich A, et al. Operative risk of mitral valve replacement: discriminant analysis of 1329 procedures. Circulation 1985;72(Suppl):II108-19.

28. Sethi GK, Miller DC, Souchek J, et al. Clinical, hemodynamic, and angiographic predictors of operative mortality in patients undergoing single valve replacement. J Thorac Cardiovasc Surg 1987;93:884-97.

29. Birkmeyer JD, Marrin CA, O'Connor GT. Should patients with Björk-Shiley valves undergo prophylactic replacement? Lancet 1992;340:520-3.

30. Kuritz SJ, Landis JR, Koch GG. A general overview of Mantel-Haenszel methods: applications and recent developments. Ann Rev Public Health 1988;9:123-60.

\section{Appendix A: Expanded methods}

Conventional angiographic systems are manufactured to operate best at $70 \mathrm{kVp}$ (kilovoltage peak) to optimize the imaging of iodinated contrast material. However, the use of radiography for imaging metallic defects requires a higher energy (kilovoltage peak) so that the metal itself is partially penetrated. This higher energy also more completely penetrates background bone, making it less obscuring. These beneficial effects outweigh the deleterious effects of increased x-ray scatter. Abolfathi and coworkers $^{6}$ have verified this effect in in vitro imaging of $\mathrm{C} / \mathrm{C}$ valves.

As a result, the Siemens Hicor-Coroskop system was modified to allow a peak voltage of $83 \mathrm{kVp}$ and a peak power of $125 \mathrm{~mA}$, using an exposure algorithm that favored peak voltage over peak power. The addition of a $135 \mathrm{~mm}$ focal length lens allowed larger valve images to be obtained on $35 \mathrm{~mm}$ cine film. Imaging on this system was performed at 30 frames per second with 4 to 6 seconds per view. An x-ray tube focal spot with a nominal size of 0.88 $\mathrm{mm}$ and a pulse width of $6.4 \mathrm{msec}$ were used. Before study initiation and before each imaging session, this system passed a Siemens image quality assurance program. A minimum of 3.7 line-pairs per millimeter visualization on the film with the film density and grading indices within $\pm 5 \%$ of specification was required before imaging began.

The feinfocus system uses nonpulsed electron gun technology, kilovoltage peak up to 180 , direct magnification up to sixfold, and a high-resolution image $(1024 \times 1024$ matrix $)$ to achieve a spatial resolution of up to 18 line-pairs per millimeter. Electron gun technology eliminates the increasing peripheral blurring associated with direct magnification and allows a variable focal spot of from $40 \mu \mathrm{m}$ to $300 \mu \mathrm{m}$. Imaging with this system was performed at 7 frames/sec with 3 -second acquisitions per view. Digital data were reviewed on high-resolution monitors that maintained the original image quality. This system underwent a complete quality assurance check by the manufacturer just before study initiation and passed the manufacturer's line-pair test before and after each use.

A 12-month period of practice and testing ensured optimal imaging techniques by two separate imaging teams, one for each system. Each team was composed of an experienced physician plus one to three technologists. Initial training consisted of practice cine film review of $60 \mathrm{C} / \mathrm{C}$ valves imaged in a mechanical phantom. ${ }^{7}$ For the feinfocus team, instruction and practice on the system itself included on-site assistance and training by the manufacturer. The team physicians passed a screening test, consisting of a series of 40 clinical studies with an undisclosed $20 \%$ SLS prevalence, as was required by the Shiley Heart Valve Research Center for its clinical screening sites.

The imaging teams practiced with a working heart valve phantom that simulated the attenuation and scatter of the human thorax and approximated normal cardiac anulus and valve motion. ${ }^{8}$ This training sample included six intentional SLSs (zero gap) and three intact $\mathrm{C} / \mathrm{C}$ valves imaged multiple times to create a randomized series of 120 sets of images with a $10 \%$ SLS prevalence.

During this same period, five sheep with $\mathrm{C} / \mathrm{C}$ valves (three with intentional SLSs and two with intact SLSs) were imaged repeatedly on both systems. After this 12 month training period, the capabilities of both imaging teams were approved by senior staff of the Shiley Heart Valve Research Center.

Seven of the eight reviewers used for the study were selected by the sponsor (Shiley Heart Valve Research Center) from the three $\mathrm{C} / \mathrm{C}$ valve clinical screening sites. The remaining reviewer was recruited from our institution from among four trained expert readers who had not participated on either imaging team. The readers included four cardiologists, three radiologists, and one cardiovascular surgeon. They assembled at a remote location, where they each independently reviewed their entire complement of 224 image sets over 3 days.

The Siemens image sets were read on Vanguard XR35 
projectors (Vanguard Corporation, Melville, N.Y.). The feinfocus images were displayed on the Sun SPARC 20 workstation (Sun Microsystems, Inc., Mountain View, Calif.) with a high-resolution monitor equivalent to that on the actual feinfocus system itself.

Interpretation was by predetermined criteria (Table I) as described in the statistical methods section. This scoring system was developed in prior phantom and sheep studies by Shiley and used in more than 890 clinical scans performed to date. ${ }^{15}$ Grading with the feinfocus system differed from grading with the Siemens system only to compensate for the differing number of frames available for viewing. Reviewers practiced using these scoring systems with test image sets representing all five grades and could refer to these examples at any time. Reviewers were monitored and were prevented from discussing any material or cases among themselves.

The image assessment grade data from each reviewer were classified as either correct (1) or incorrect (0) for each image set read on each of the two technologies (Siemens, feinfocus) for each valve within the image set and block. Because of the repeated measures (reviewer, block, image set) for each valve, we used a stratified Mantel-Haenszel method, ${ }^{30}$ adjusting for reviewer, block, and image set, to estimate the average odds ratio, as well as its $95 \%$ confidence interval, for the likelihood of the feinfocus system detecting an SLS relative to the Siemens technology. Estimates were produced for clinical SLS valves, intentional SLS valves, and for all SLS valves. Similarly, this same method compared specificity of the two technologies for the normal valves. These odds ratios were adjusted to control for reviewer, block, and image set. A paired $t$ test was used to compare the radiation levels between the two imaging technologies. All calculations were performed with the use of the SAS statistical package (SAS Institute, Inc., Cary, N.C.), StatXact statistical package (Cytel Corporation, Boston, Mass.), and S-Plus (MathSoft, Seattle, Wash).

\section{Availability of Journal back issues}

As a service to our subscribers, copies of back issues of The Journal of Thoracic and Cardiovascular Surgery for the preceding 5 years are maintained and are available for purchase from Mosby at a cost of $\$ 16.00$ per issue until inventory is depleted. The following quantity discounts are available: $25 \%$ off on quantities of 12 to 23 , and one third off on quantities of 24 or more. Please write to Mosby, Inc., Subscription Services, 11830 Westline Industrial Drive, St. Louis MO 63146-3318, or call 800-453-4351 or 314-453-4351 for information on availability of particular issues. If unavailable from the publisher, photocopies of complete issues may be purchased from UMI, 300 N. Zeeb Rd., Ann Arbor, MI 48106, 313-761-4700. 